\title{
Towards Sensorial Approaches to Visual Research with Racially Diverse Young Men
}

\author{
EMMANUEL TABI \\ OISE/University of Toronto, Canada
}

JENNIFER ROWSELL

Brock University, Canada

\begin{abstract}
This is a collaborative ethnographic research project that highlights the artistic, literary contributions of racially diverse young men. It uses Critical Race Theory to question conventional, Eurocentric educational approaches that historically and currently continue to suppress various socially and culturally learned modes of communication. This article presents two research projects in urban and suburban formal and informal educational institutions to highlight multimodal literary approaches. The first project is an amalgamation of two critical, ethnographic case studies that explores how racially diverse young men express their literacy through rap and spoken word poetry. The second project uses ethnographic methods to observe racially diverse young men's production of films and photographs in high school, community centers, and art gallery spaces. This study uses visual methods coupled with affect and sensory-laden approaches to collect data and conduct an analysis. The article reflects on conversations surrounding young men, particularly racialized young men, their relationship with literacy, and how these conversations are founded on their failure and deficit language about their literacy repertoires. We believe that such research is closely tied with other social justice themes and modes of inquiry. This article steers away from the ways racialized young men do not use literacy, and focuses instead on the ways that they do use literacy. Their literacy practices are predominantly visual in nature, frequently accompanied by other modes such as words and moving images. Fitting within the scope of the special issue on social justice and visual methods, we argue for a greater acknowledgement and analytical gaze on sensory and affective nuances within visual research. This approach adds texture and volume to interpreting racialized young men's narratives. Interrogating their visuals and talking through their narratives that have agentive qualities gives both researchers an awareness of young men's emotional worlds, and how the visual allows for sense-laden, agentive meaning-making.
\end{abstract}

KEYWORDS visual methods; multimodality; race; literacies; embodiment; affect; ethnography 


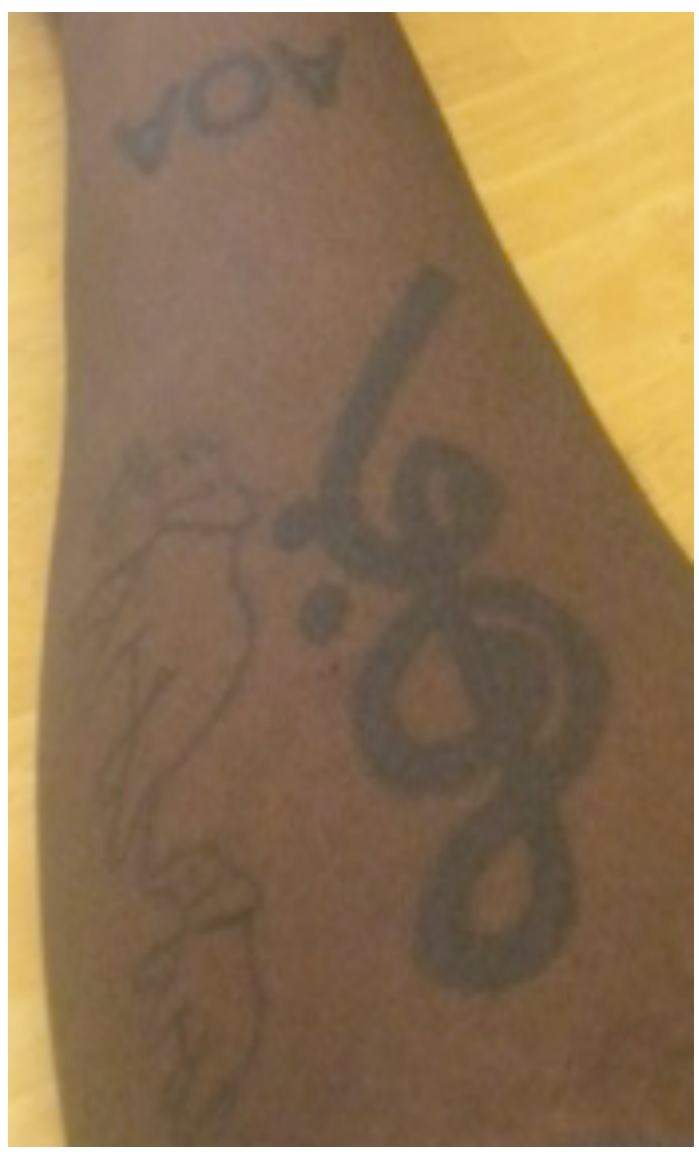

Figure 1. Emmanuel's Tattoo

The image of the mother and baby elephant on the bottom of Emmanuel's arm serves as a fitting segue to our article (see Figure 1). It combines visual methods with sensory and affect-laden approaches to data collection when investigating racially diverse young men's literacy practices. In our respective research, we turned to affect theory and to embodiment (Enriquez, Johnson, Kontovourki \& Mallozzi, 2015; Leander \& Boldt, 2013). These theories complement our ethnographic inquiries with racially diverse young men. Emmanuel's tattoo has strong personal connections for him because it is a tribute to his Mum who passed away a few years ago. To an outsider, the tattoo may appear cute, maybe even novel, but to Emmanuel it is laden with memories, senses, and emotions that are still palpable and raw for him. The mother-baby elephant is an artifact of his identity, a visual reminder of lived memories imprinted on his skin. His Mum called him "her little elephant" as a 
child, and Emmanuel had the image imprinted on his skin as a continual reminder of her. The visual of Emmanuel's tattoo and this brief reflexive framing illustrate the research approach that we take in our work with young people when we examine the ways in which they value or produce multimodal artifacts (Rowsell, Kress, \& Street, 2012; Pahl \& Rowsell, 2010).

This research adopts visual methods (Mitchell, De Lange, \& Moletsane, 2017; Rose, 2007) combined with sensory ethnography (Pink, 2009) to examine human-made and image-based productions by racially diverse young men in formal and informal contexts. The research is ethnographic with a focus on multimodal repertoires of practice as key sources. These include a variety of texts from short films (Rowsell \& Decoste, 2012), photographs (Rowsell \& Vietgen, 2017), and body art (Rowsell, Kress \& Street, 2012). Given the increasing discourse around failure and racially diverse males, there must be more research that examines the complexities and depth of racially diverse young men's vernacular literacies seen in their musical compositions, graphic narratives and image-based work.

The article is structured as follows: first, we examine the social functions of literacy; second, we focus on race and literacy to identify a research and writing gap about the nature and properties of racially diverse young people's meaning-making; third, we present background on the tradition of ethnography within Literacy Studies followed by an account of the affect turn in Literacy Studies; fourth, we outline our application of ethnographically driven visual and sensory methods of data collection; fifth, we feature vignettes from our respective research studies; and finally, we conclude by highlighting the importance of paying attention to, and connecting with, the ways in which many Black young men express their lived experiences and communicate their stories. This research suggests the need to apply affectdriven, sensory lenses on research with youth broadly, as well as with ethnically and culturally diverse youth more specifically.

\section{The Social Functions of Literacy}

Although the balance of many social institutions has shifted, there remains a history of cultural and political hegemony over the social functions of literacy (Graff, 1982). By "literacy," we refer to competencies associated with conventional definitions associated with educational institutions, such as reading, writing, speaking and listening. Equally important are contemporary communicational competencies associated with social media and digital texts. By "the social functions of literacy," we refer to the actions or practices that we engage in, when, where, and with whom. The social practices of literacy elicit some of the motivations, interests, and what Barton and Hamilton (1998) describe as "ruling passions" behind literacy. The social dimension of literacy offers a wider range of communicational practices, and a more expansive sense of what counts as literacy. 
The transition from pre-industrial social orders to class societies meant that the role of the school as a maintainer of social stability increased. Literacy was used to promote values, attitudes, and habits considered vital to the maintenance of social order (Graff, 1982). Such factors led to a devaluation of non-European cultures, despite the abundance of rich cultural and oral history (Gee, 1986). Many children of low-income and minority households failed to gain the literacy skills taught in school (Gee, 1986). By association, these children also failed to gain social and intellectual value from their peers.

An understanding of where literacy happens shifts when definitions expand. Homes, communities, and work places become sites for literacy practice (Hull \& Schultz, 2002); however, problematic curricular practices persist to delegitimize these unconventional contexts and the literacies youth engage with outside of the classroom (Kinloch, 2010). For many young people, what happens outside and inside of school is a complex hybrid of literacies. Lines between what is learned and where it is learned are blurred, fluid, and dynamic (Fisher, 2003; Kinloch, 2010; Kirkland, 2013).

Typically, the literacy strategies used among racially diverse students and their communities is deemed deficient based on traditional definitions, framings, and measures of literacy competence (Paris, 2012). Personal literacies include individual histories, gender, ethnicity, culture, and engagement in social worlds (Kirkland, 2009). The logic of multiliteracies recognizes meaning-making as an active and transformative process. It offers a pedagogy that can influence global change that is supportive of diverse approaches to literacy (Cope \& Kalantzis, 2000). The literacy practices of young people of color, particularly Black men, is an area that is understudied and requires our attention as researchers (Kirkland, 2008). Similarly, within Literacy Studies, there are "increasingly limiting definitions of what counts as legitimate literacy research" (Morrell, 2006, p. 61). Due to a lack of representation of non-white students in international curriculum and the hegemonic Eurocentric educational approaches, many students of color lose the aspiration to excel in the classroom (Morrell, 2006). They use alternative strategies to tell their narratives, and engage with literacies that are more meaningful to them (Mahiri \& Sablo, 1996). These literacy strategies include, for example, rapping, spoken word poetry, and breakdancing (Fisher, 2003; Hudson \& Tabi, 2015; Kirkland, 2013; Stovall, 2006).

\section{Critical Race Theory and Literacy Studies}

Critical Race Theorists recognize race as a fluid social construction which significantly influences how people are read and understood (Ladson-Billings \& Tate, 1995; Lopez, 2000; Solorzano \& Bernal, 2001). Critical Race Theory recognizes that racism is part of our everyday social lives. It identifies power structures and discourses that are founded on white privilege (LadsonBillings, 1998; Solorzano \& Yosso, 2002). Race continues to dictate how 
individuals are organized and identified (Parker \& Lynn, 2002). Critical Race Theory in many ways is predicated on the formation and exchange of racialized people's narratives and lived experiences (Ladson-Billings, 1998). Paying attention to such narratives is significant in order to examine and challenge conceptualizations and discourses on race and racism (Yosso, 2005). The process through which individuals and groups are racialized speaks to the "... social interaction, positioning, and discourse" (Nasir, 2011, p. 5) that reinforce the methods by which meaning is given to individuals and groups based on pre-existing racial ideologies and stereotypes (Dei, 2006).

Racism is a plague that affects many people of color from childhood, often resulting in cycles of trauma (James, 2010). Although racialized bodies challenge and resist institutions and structures of racial oppression, there is an emotional cost for resistance (Dei, 2006). Thus, it is imperative that people of color continue to express narratives that resist hegemonic neoliberal notions of race (Gosine \& Tabi, 2016; Parker \& Lynn, 2002) by presenting narratives that reflect the cultural value of their communities (Yosso, 2005).

There is a tendency in curriculum, pedagogy, and more traditional framings of educational learning to resist students' out of school literacy practices (Haddix \& Sealey-Ruiz, 2012; Kirkland, 2013). However, Kinloch (2007) demonstrates how youth voices are continually filled with narratives that provide a glimpse into their lived experiences, politics, and broader social understandings. Youth continually transform literacy to satisfy their own cultural concerns and interests (Street, 1993). These narratives are fluid, often taking the shape of symbols and tattoos (Kirkland, 2009), digital literacies (Kinloch, 2007; Kirkland, 2008), rapping, breakdancing (Hudson \& Tabi, 2015), spoken word poetry (Fisher, 2003) and playwriting (Winn, 2010). We use a critical literacy lens to meet our youth where they are, and observe the meaningful, intense ways they use literacy to tell their narratives (Pahl \& Rowsell, 2011) and navigate their identities (Kirkland, 2008).

We each have experience working with racially and ethnically diverse youth (Gosine \& Tabi, 2016; Hudson \& Tabi, 2015; Pahl \& Rowsell, 2010; Rowsell, 2009) in Canada and the United States. We previously focused on racially and ethnically diverse males, and examined multimodality through an ethnographic research lens. In the sections that follow, we argue for more sensory approaches to visual, multimodal-ethnographic research to access hidden knowledge, epistemologies, and connections between participants and researchers.

\section{Race, Racialization and Education}

Interpretations and representations of racialized individuals are often typecast and problematic (Dei, 2006). They continue to be rooted in very particular hegemonic and colonial histories, which demand critical unpacking (Walcott, 2012). Traditional representations of Black men are habitually based on 
problematic stereotypes (Cooper, 2006). As a result, the journey from childhood to adulthood for many Black people revolves around traumatic moments due to racist encounters, which become increasingly overwhelming over time (James, 2010).

Instead of ignoring racial identities, a key component of Critical Race Theory is centralizing the intersectional narratives of racialized individuals. Critical Race Theory critically examines historical and contemporary power dynamics that marginalize and devalue narratives of racialized people (Parker \& Lynn, 2002; Sorlozano \& Yosso, 2002). When critically examining his journey as a Black male educator within a White supremacist society, Johnson (2017) explains that disrupting principles of anti-Blackness required him to "illuminate the literacies [his] Black male body [brought] to the classroom" (p. 477). For racialized educators, experiences in educational institutions provide a reflection of previous social encounters with racism. These experiences serve to structure and shape the discourses that narrate racialized educators' lives and identities (Johnson, 2017). Although some may argue that we live in a post-racial society, the attitudes that encourage the violent damaging and dehumanization of Blackness continue to traumatize Black people. They also serve to destroy our spiritual, emotional lives through devaluing Black lives. This is further propagated by educational curriculum taught to Black students (Johnson, Jackson, Stovall, \& Baszile, 2017).

Such racial underpinnings influence how Black students, particularly Black males, are "treated in classrooms and often leads to how Black males are ultimately treated in the academy and society" (Johnson \& Bryan, 2017, p. 164). Through the functions of white supremacy and slavery that positioned the Black body as white property, the Black male body is often deemed as requiring control. The Black body is repeatedly criminalized, marginalized and degraded, leading eventually to many Black people's "spiritual murder" (Johnson \& Bryan, 2017, p. 165).

Black youth use creative modes of communication as they often (re)create and adopt the English language based on social and cultural experiences with language in their communities. Slang is often heavily policed by teachers, who may devalue, silence and at times destroy this fascinating (re)creation of language. Many Black youth contribute to the classroom, while at the same time having to exalt the lives and histories of Europeans (Johnson et al., 2017). This Eurocentric curriculum "ignore[s] and fail[s] to acknowledge Black cultural ways of knowing" (Bryan, Johnson \& Williams, 2016, p. 490). It is imperative that teachers, specifically English teachers, are educated on the various means by which Black students express themselves. The classroom is meant to be a safe space where students should feel free to express their unique ideas based on their own social-cultural understandings of language. This is a step towards resisting the harmful monolithic, homogeneous, and stereotypical representations of Blackness and Black life in broader society (Johnson et al., 2017). 
During Emmanuel's time conducting fieldwork, he sat with young male participants and listened to their powerful narrations of how social oppression has impacted their lives. Primary forms of social oppression include patriarchy, racism, and poverty. As will be discussed later in the article, the narrative of participant Ebele parallels Johnson's (2017) notion of a "symbolic and spiritual death" (p. 61). A "symbolic and spiritual death" is defined by the moments Black children and youth assimilate to educational institutional norms that are based on Eurocentric curriculum and ideologies (Johnson, 2017). Students often feel forced to suppress parts of themselves that are influenced by lived experiences in their communities.

Ebele's experiences were painful to listen to, specifically in moments that paralleled Emmanuel's own personal experiences. However, Ebele's response to oppressive moments, and his embodied resilience, provide a powerful and inspiring model. Ebele chose to humanize himself after surviving an education system that in many instances worked to dehumanize his hopes, dreams and aspirations. Ebele humanized himself by expressing his pain through literacy practices in visual art and poetry. These are artistic contributions to culture, which solidified Ebele's personal passions and rekindled a new pedagogical approach through artistic activism. Ebele's artistic healing led him to find empathetic and powerful strategies to inspire healing and growth in other youth in his community.

\section{Adopting Ethnographic and Multimodal Research}

In the article, narratives of race, racism, and multimodal literacy practices are coupled with our own ethnographic and highly visual approaches to data collection. This article draws on research that we each conducted with young people in urban and suburban contexts. To conduct ethnographic research, we document the role of culture, identities, practices used, and we examine the social dimensions of our research by looking at the social uses of literacy. More specifically, we examine multimodality, by which we mean studying how participants combine modes to represent meanings. A mode is one particular form in which it is possible to represent an idea. Sometimes it is easier to put an idea into a drawing rather than a piece of writing. We find that ethnography helps situate our research and participants in their urban and suburban contexts. Multimodality provides a more systematic way of analyzing modalities in texts.

Emmanuel's research is a critical ethnographic case study that explores the narratives and lived experiences of four African-Canadian Black Young Men in the Greater Toronto Area. These men contribute to significant conversations about Black masculinity and education beyond traditional realms that have previously failed them. The narratives of these men resound with examples of resistance, self-determination, resilience, and success when confronted by racism and marginalization. The issue at the center of 
Emmanuel's project is that educational institutions continue to be difficult for Black Young Men to succeed, in both Canada (Dei, 1997; Gosine \& Tabi, 2016; James, 2012) and the United States (Kirkland, 2013; Ogbu \& Simons, 1998; Yosso, 2005). In Toronto, Canada, Black Young Men continue to have some of the lowest average measured academic performances, specifically from the grades 7 to 12 (Toronto District School Board, 2007). Emmanuel's research project examines how four Black Young Men each created and championed a separate after school workshop to address issues of low selfesteem, depression and marginalization among children and youth they encountered in the schools and communities where they work. These young men used their skills as spoken word poets and rappers to engage, motivate, and educate the children and youth. The four racially diverse young men created a sense of "wounded healing" (Hill, 2009) in their workshops. This project is grounded in the experiences of these four young men as they embrace their roles as artists, educators, and activists. They use rapping and spoken word as tools to help build up the communities they live and work in. As a spoken word poet for the past 13 years and a musician within Toronto's artistic community, Emmanuel has witnessed first-hand how meaningful rapping and spoken word poetry is to the lives of many Black Young Men.

To complement Emmanuel's research, Jennifer presents an ethnographic study with Black Young Men in formal and informal educational contexts. This includes high schools, community centers, and art galleries. Jennifer's research documents participants' multimodal practices in the diverse sites, through thick description (Geertz, 1973). The men featured in this portion of the study are between the ages of 15 to 17 . As a researcher, Jennifer sits alongside participants as they develop multimodal productions as a part of their units of study in English and Media Studies classes. Jennifer observes and speaks with them as they produce films and photographs, or engage in literacy practices more generally. This ethnographic approach entails documenting participants' reactions, facial expressions, gestures, and observed thought processes that signal particular ways of making and knowing. In this way, ethnographic methodology relies heavily on expressive and sensory-laden practices in the production of texts. From such work, Jennifer has identified expressive, embodied work as expressive of identity practices (Rowsell \& Pahl, 2007) that become texts. Adopting visual and ethnographic methods provides an opportunity to explore subjective dimensions of multimodal productions.

In this article, we collaborated with a common purpose of exploring sensory-led approaches to visual and multimodal interpretative frameworks. Sensory methods provide an exploratory approach to interpret young people's multimodal productions. We combine our separate research to extrapolate a more affectively driven analytical gaze onto visual ethnographic work. Our work coincides with Pink's (2011) claim that sensory ethnography deals with knowledge that cannot be understood only through observation. Sensory ethnography includes observations, talk, and visual analyses. In this study, we 
interpret how participants embed their felt sensibilities, memories, interests, and convictions into multimodal work.

\section{Sitting Within an Ethnographic Tradition}

There is a long-standing tradition of conducting ethnographic research to examine the nature and properties of literacy practices (Heath, 1983; Street, 1984). Often associated with New Literacy Studies (Rowsell, 2011; Grenfell et al., 2012), ethnography appeals to literacy researchers due to its grounded focus on cultures, identities, practices and varied texts. Particularly important to ethnographic researchers is what supports and constrains accomplishments of participants, as well as the broader issues of access to literacy practices (Bloome \& Green, 2015). Ethnographic accounts of literacy and language practices uncover power dynamics. They dictate what counts as legitimate literacy processes and practices within specific social groups. More conventional ethnographies within literacy research focus on documenting cultures, texts, contexts, and social practices. They do not focus on ephemeral, emotional or embodied aspects of literacy and language practices. Such work locates the researcher's position and reflexivity alongside observations about where studies are located, what is done, what texts are accessed and circulated, and how people interact. What is distinct about applying ethnographic methods within literacy research has been taking what Green and Bloome (1997) call 'an ethnographic approach.' Adding this approach to an ethnographic research inquiry, Green and Bloome (1997) underscore that many university-based literacy researchers apply ethnography in a more compressed way to examine everyday literacy life in and out of school. Both of us adopt ethnographic approaches to our research and use visual methods to conduct such research. Jennifer has steadily introduced photography and film into her ethnographic work in schools. This is based on her observations that many young people gravitate to visual approaches to find their voices (Rowsell \& Vietgen, 2017).

\section{Applying a Visual and Sensory Research Gaze}

In this section, we foreground ways that we have combined visual/representational methods with sensory and embodied/nonrepresentations methods. Combining sensory approaches with visual research has allowed us to move beyond images and materialities to analyze more ephemeral qualities that are harder to apprehend and hold on to. This can facilitate a greater understanding of participants' experiences developing photography and moving images, in relation to how a researcher experiences speaking with and observing them. Pink (2009) understands experience and meaning-making as apprehended through a sensory, materially-situated lens. 
Scholars like Finnegan $(1986,2002)$ have looked at conceptions of literacy and language among a variety of cultural groups. They question the linguistic reification of literacy in Western cultural assumptions.

Pink $(2009,2015)$ recognizes the significance of sensory ethnography. It is an active listening approach that includes observation and analysis of a participant's non-linguistic modes of communication. A visual-sensory ethnography focuses on the sensory nature of visual methods. These entanglements can go beyond a notion of what is "real" and "known" under the terms of realist social science. It provides an opportunity to connect to the narratives of participants and the objects in those narratives. Somerville (2008) writes about sensory responses to objects and landscapes, and their relationships with space and place. In a sensory approach, we draw attention to researcher and participant relationships, connections, and affinities. We argue that visual research, whether it is taking photographs or working with young people doing visual work, calls on emotions and embodied reactions that are worth examining

Senses emerge during ethnographic fieldwork and they are strongly connected with the fieldnotes taken, analytical codes, and determined themes. Our research includes sharing the experience of data collection and analyses with participants. Ebele, TD, Ahmed, Jasper, and Jamal are racially diverse young men who produce knowledge based on their interactions and experimentation. ${ }^{1}$ This makes it critical to include a sensory approach to conduct visual research. Conversations about multimodal productions are integral to a sensory-visual method. In the section that follows we introduce racially diverse young men who find their voices and emotions in the visual.

During the process of conducting research with racially diverse young men in formal and informal educational institutions, it became apparent that writing field notes was not enough to capture the complexity of their work, especially as this community often feels marginalized in education institutions which may prevent it from actively engaging and producing content. As a result, we began to fold more affective (as in feelings) and embodied (as in bodily responses) orientations into our respective interpretations. In our application of affect and embodiment, we view affect as an individual's way of being moved by something (Massumi, 2002) and embodiment as bodily responses (Enriquez et al., 2015). Scholars in Literacy Studies such as Ehret have described moments when people affectively respond to media making as exhibiting affective digital encountering (Ehret, Hollet, \& Joicus, 2016). Distinct from traditional ethnographic approaches, we argue for visual methods informed by a sensory-embodied analytical approach. When young people produce visuals, they express their emotions clearly, strongly, and determinedly. This research suggests that racially diverse young people

\footnotetext{
${ }^{1}$ We use pseudonyms to protect the identity of participants in our research studies.
} 
exhibit engaged and responsive embodiment with the work they produce. This embodiment is non-representational, and therefore not always evident.

Our argument therefore rests on an affect turn in Literacy Studies that acknowledges the role of affect, resonance, and embodiment within everyday meaning-making. Researchers who pursue affect within literacy research seek to uncover more ephemeral, non-representational forces that are part of meaning-making. This is an alternative approach to literary research that predominantly focuses on representational forces (Leander \& Boldt, 2013; Lewis \& Tierney, 2013). Such work aligns well with insights generated based on an ontological turn (St. Pierre, 2013). A sensory ethnographic approach focused on affect illuminates how literacy is diverse, animated, and evocative.

\section{Excavating the Sensory in Research Vignettes}

To illustrate our efforts to locate senses within our ethnographic and multimodal fieldwork, we present vignettes and short narratives from two research projects involving Black Young Men. These illustrate the two researchers' somewhat different visual, sensory and ethnographic approaches.

During fieldwork, Emmanuel adopted the strategies of one of the young men with whom he worked. Whenever this young man engaged in community organizing and activism work, he initiated gatherings with a community meal. Through the process of cooking or choosing a place to eat, Emmanuel was able to learn about some of the cultural customs and practices of these young men. He also shared his own experiences based on the comfortable environment that the shared meals created. The initial exchange of ideas, histories, narratives, and strategies created an emotional opening. Further exchange of ideas led to a dialogue about who they are, who they have been, and who they dream of becoming. This process led us to speak about how Blackness is not a monolithic experience. Instead, it is an experience spoken to and influenced by countless cultures, as well as variations of African identities.

Through these relationships, the young men in Emmanuel's study spoke to him about the narratives behind their cultural production. These young men invited Emmanuel to accompany them to their performances, graduations, visual art presentations, and celebrations. These moments allowed synergies to emerge. Emmanuel and the young men shared a collective resistance based on their lived experiences marked by distinct physical, emotional and spiritual journeys. As these relational bonds became stronger, Emmanuel conducted in-depth interviews and focus groups interviews with the young men. Focus groups were conducted after the in-depth interviews to allow the young men to further articulate the issues shared in their interviews.

Over the years, Jennifer has modified her ethnographic approach to include multimodal scholarship and highlight multiple modes at work in research sites. Focusing on what she collects and how she collects it steadily became 
central to her research inquiry. A decade ago, Jennifer entered a site with an eye to its culture, to the identities in a space, to the types of texts on display, in circulation, to the broader ideologies at play within conversations, and etched within artifacts. In recent years her method has become more relational. Although she has not shadowed participants in the same way that Emmanuel has, she has had longer conversations with participants, and has co-produced her own texts alongside participants. In the past, Jennifer emphasized and interpreted the final products, whereas nowadays she focuses far more on processes and epistemologies.

In her earlier work, she wrote field notes (Wolcott, 2001), took photographs, conducted interviews, and collected textual artifacts with a focus on how individuals mediated and materialized modes in texts. Presentday Jennifer concentrates more on assembled approaches to data collection, privileging the experience, shape, and properties of multimodal work. This includes collaboration with educators, arts professionals, and young people to produce static visuals and moving-images. She focuses on both nonrepresentational and representational aspects. What visuals do young people choose in the moment and why? What guides their sensibilities, bodily engagements, and sentimental responses? Admittedly, such work entails conversations, interviews, observations, and artifact collection. However, what supplements this corpus of data is unrehearsed, impromptu, felt accounts by educators, professionals, and research participants. Once a text is produced, Jennifer sits with the producer and talks through its materialities.

\section{The narratives we keep close and the friends we never leave behind}

Like the image of Emmanuel's tattoo that began the article, Emmanuel regards the artifacts and photographs that his participants share as artifacts of identity that unfold narratives. Emmanuel learned from participants that cultural production materializes emotions, memories, and felt experiences. Ebele hides his secrets in his poetry. He uses his poems to connect with other youth who grew up in his immigrant working class neighborhood west of Toronto. Emmanuel believes that some people keep artifacts outside of their bodies, on their bodies, and even in their bodies. They pull them out when it is safe to examine, to write about, testify their hopes, dreams, and memories. Ebele is a visual learner, and was once considered gifted by his teachers. He often drew out his math problems as a means to decipher the question, thus allowing him to better understand his school work. Unfortunately, a teacher viewed this as doodling, and made Ebele stop drawing during his math tests. From this moment on, Ebele could not understand the written math problems on his math tests, and subsequently began to fail his math courses. Ebele was then labeled as a problem child, rather than as one who had difficulty learning. The Eurocentric curriculum did not provide flexibility for a student who learned differently than traditional educational standards. After years of 
struggling with school, Ebele dropped out. Although he returned to school a few years later painful memories remained, due to his previous difficulties in school. The following text is an excerpt from one of Ebele's poems. This poem reflects Ebele's thoughts as he finds himself maturing throughout his youth:

As time doesn't make things change, instead change occurs in time.

As time is never too late nor too soon.

I use to play life high, but then I took it low like a note on a bassoon.

With every old trial I've faced and tribulation that's new

I remember that seasons do change, just as tides rise with the moon.

Likewise everyday that I wake, the strength of my wings are renewed

just like a Butterfly coming out of its cocoon.

This poem expresses Ebele's "coming of age" process, which he describes as being similar to a butterfly "coming out of its cocoon." Emmanuel has known Ebele for eight years. They first met outside of a poetry venue where Emmanuel was performing his spoken word poetry. Ebele was a teenager who expressed himself through rapping, spoken word and visual art. After Emmanuel's performance Ebele and TD began sharing their poetry and rap lyrics with one another, embracing their synergistic creative flow. Over the years, Emmanuel and Ebele continued to spend time together and met at other poetry events.

Emmanuel has witnessed Ebele's transformation from a young man filled with potential to one of Toronto's most innovative and exciting spoken word poets and visual artists. The initial exchange of creative ideas led Ebele and Emmanuel to establish a friendship, which involved continually exchanging songs, poems and music. They developed an artistic exchange that nurtured and encouraged further artistic expressions. Ebele and Emmanuel continually supported each other by consistently attending each other's performances. When Ebele wrote this poem, he was in a transitional period in his life. $\mathrm{He}$ was examining who he was as an artist and a young Black man. He was also questioning his role in society, and the contributions he wanted to make to help other youth of color navigate their lives. Ebele developed this poem to communicate the difficulties he faced in his life, specifically in educational institutions that did not address his needs as a visual learner. When provided with opportunities to use his gifts of visualization, Ebele excelled in the vivid imagery presented in his poetry. Ebele's poem mirrors the difficulties he faced both inside and outside of school. It also suggests the hope inspired from his more recent success as a visual artist and a poet.

As Ebele's agency grew, he gained control of his life and became increasingly intentional about the decisions he made in and out of school. Ebele returned to school to complete his high school degree. He felt that with a better education he would be able to take advantage of the opportunities that were presented to him. Ebele also hoped to establish a precedent within his community to show other youth that they can resist and overcome many 
difficulties they face. As Ebele got older, he continued to experience a renewal of strength and rejuvenation that allowed him to overcome the "tribulations" he has survived. He is determined to be an example of hope, resistance and resilience for other youth growing up in Toronto's urban communities.

Poetry is one of a few ways that the Black Young Men in Emmanuel's study have expressed and articulated difficult moments in their lives. Through artistic rapping, painting, spoken word poetry, and tattooing, these young men narrate their lived experiences. They express the joy, pain, sorrow, wisdom, and strength that permeate their lives.

Ebele's artistic expression stems from tremendous creativity, which he displays in artistic improvisations such as African drumming, spoken word poetry, and visual art. As a spoken word poet and musician, Emmanuel creates music and poetry alongside Ebele, particularly during difficult times. After losing his mother, Emmanuel often shared his music and poetry with Ebele as a form of healing. This exchange was founded in processes of "wounded healing," (Hill, 2009, p. 265) which allowed Ebele and Emmanuel to share moments of pain and hope, and support each other during the most difficult moments.

TD is another young man in Emmanuel's study who uses his rap lyrics to speak to his lived experiences, as well as his hopes, dreams, triumphs, and disappointments. Emmanuel met TD a few months before he met Ebele. The day Emmanuel met Ebele outside the poetry venue, TD came to the venue to watch Emmanuel perform. An artist friend who thought they should collaborate artistically, introduced TD to Emmanuel. Over time, their friendship grew as they collaborated on songs, rap lyrics, and poetry. This artistic exchange led them to open up to each other about their lived experiences, as well as their strategies for overcoming social issues such as racism. TD and Emmanuel shared a passion for the betterment of Black youth they interacted with in Toronto's arts community. Furthermore, they had both recently lost two of their best friends. By sharing their experiences of pain and loss, Emmanuel and TD began to secure a deep and meaningful friendship. TD's rap lyrics are filled with tributes, acknowledgments, and deeply meaningful references to one of his best friends who passed away eleven years ago. TD and his friend were both racialized youth of Caribbean descent who together traversed the harsh realities of poverty and violence. They drew on each other's strength and wisdom in order to survive the difficult environments and situations presented to them in Toronto's urban environments. These experiences served to strengthen their bond as friends, and in many respects as brothers. When TD's friend died, TD expressed that it was as if he lost one of the most important parts of himself. The passion TD continues to have for his friend is perpetuated through the ways he mentors other children and youth who are raised in similar environments as he was. When TD speaks of his friend, the grief is palpable, but so is his commitment to honor his life. TD gives tributes by expressing his friend's humor and 
uncanny wisdom, two qualities that he strongly valued in his friend. Harnessing his mentoring work with youth to the memory of his friend, TD seeks ways to support younger men of color.

In addition to TD's rap lyrics, which are a testament to the closeness he felt towards his friend, TD also communicates his respect and love for his friend visually. He does this with his tattoos, one of which is a mural tattooed on his right forearm. The tattoo is an outward representation of the grief, pain, and love TD feels for his friend. The tattoo is filled with sensory materiality (see Figure 2).

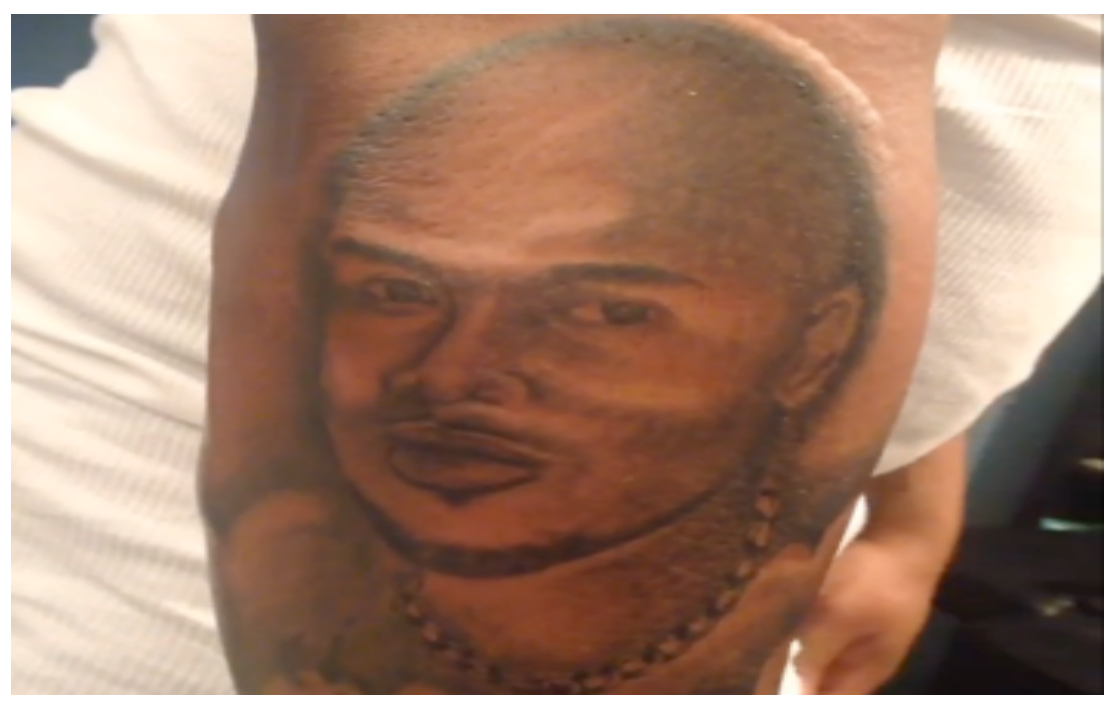

Figure 2. TD's tattoo of his friend

Like Emmanuel, TD's tattoos are a creative, visual expression of grief, hope and pain for the loss of a loved one. On multiple occasions during an indepth interview, TD references his desire to honor his friend who passed away 11 years ago. TD spoke about his friend when rapping privately with other rap artists. He spoke about how strong bonds of commitment, joy, and hope he shared with his friend helped him become the young man he is today. The pain that he endured to get the tattoo reflects the pain that TD felt, but also speaks to the inability of death to break this bond. Using ethnography as a method of inquiry encouraged Emmanuel to be part of the lived experiences that TD and the other young men shared with him. In time spent with TD, Emmanuel often reminded TD that not every emotion needs to be recorded or analyzed, but that every emotion expressed by these young men needs to be felt. 


\section{Untold narratives of felt and material repertoires of practice}

Throughout her research career, Jennifer has encountered many ethnically diverse young men who have hidden literacies (Rowsell \& Kendrick, 2013). These literacies are often rendered silent by tight framings of literacy and meaning making in educational institutions (Rowsell \& Pahl, 2015). These young men write poems, design tattoos, produce short films, are professional gamers, but they hesitate to share these meaning-making practices with educators. Sometimes educators see vestiges of these practices in their school work and foster them (Rowsell \& Vietgen, 2017), but often the creative practices are silenced (Dénommé-Welch \& Rowsell, 2017). Reflecting on her research with teenagers, Jennifer has encountered a number of designers, artists, and makers who discuss meaning-making in relation to ideas and emotions. With her burgeoning sensory-affective approach to ethnographic fieldwork, she notices more specificity and detail to support her findings.

To unveil some of these sensory-laden, untold multimodal productions, Jennifer offers three vignettes from her research. The first young man is 16year-old Jasper, who was indifferent about a Media Studies class that Jennifer observed him in at his secondary school in a small city outside of the Toronto area. When Jennifer and the Media Studies teacher introduced the assignment that asked him to create a Cindy Sherman-type conceptual photograph about a place that means something to him, he found it challenging to isolate one specific spot. At the time, Jasper loved skateboarding, and talking about meeting his friends in the skateboard park. The day that Jennifer worked with Jasper, they talked, chose props, outfits, and had conversations about Jasper's interests, as well as his everyday life. Jennifer and her colleague suggested that he capture his mood in the skate park. The resultant photo shows Jasper with an indifferent look staring at the viewer with graffiti in the background (see Figure 3).

Jasper admitted to Jennifer that he felt disengaged from school and experienced some struggles personally that distracted him. What stood out for him was a place where he felt he could be himself. In his artist statement, he explained the mood of the shot:

My portrait we did at the local skate park. I like that I chose to do my portrait here because I've spent a lot of time here and I think that it describes me the best out of anything in my town. Also, it's great because behind me is graffiti and I love graffiti and art. I think it describes me the best. Also, I love my face because I think it tells who I am perfectly blank stare ready to take on the world by myself. It's me against the world. This park is pretty much a big part of my life. (May 2014) 


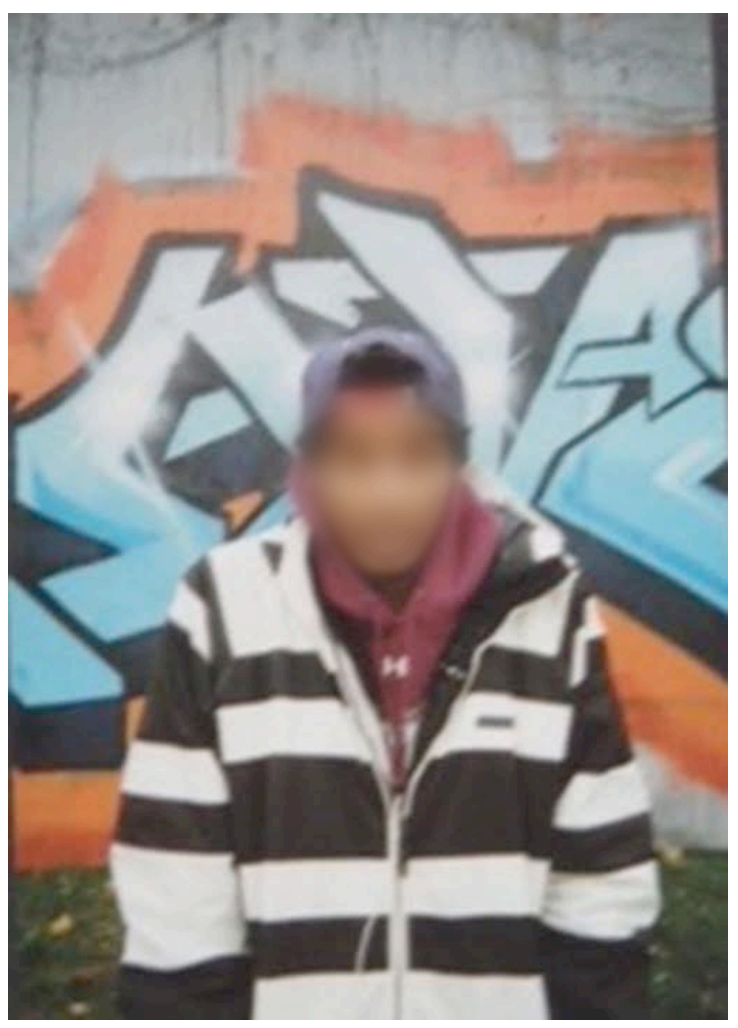

Figure 3. Jasper at the skate park

He feels like himself in the park based on a sense of authenticity and peace of mind it creates. The park represents his social space, where he meets with friends, boards, and cycles. Jasper produced a conceptual photograph that is strongly informed by embodied senses and his passions. The affect that Jasper describes has to do with a place, colors, practices, objects, and with sedimented identity (Rowsell \& Pahl, 2007) in his community. Jennifer had a connection with Jasper after their first meeting. Jasper joked that he did not really want to be in the class, and Jennifer asked him to talk about some historical icons whom he admires. He said that he would like to pose as Abraham Lincoln, and then subsequently chose items from the costume pile to dress him up. He and Jennifer then took several posed photos in what he imagined to be Lincoln's character. Jasper did not attend class for approximately a week after they worked on his photograph, but he texted his teacher to say how much he enjoyed working on the conceptual photographs. It was through Jennifer's conversations and her work with Jasper on visuals and his photocomposition that she recognized a becoming of sorts. Although 
the skateboard shot was one of the shots that they had rejected, Jasper returned to it and featured it at an art exhibit.

There is a similar degree of intensity and emotion in Jamal's rant about the expense of running shoes endorsed by star athletes. Jamal and Jennifer gradually got to know each other, and some of their shared musical interests connected them. For his assignment, Jamal produced a short video that was a rant about the exorbitant cost of running shoes. He explained how he and his friends can no longer afford to buy them, and as a result, why they wanted to boycott them. He recorded and re-recorded his short video several times until he was completely happy with it and the final product. The short video is filled with passion and some degree of anger about the divide between rich and poor. Jennifer talked to the group of young men working on their rants. Jamal particularly stood out because he passionately communicated social inequity issues, including differential access to desired objects. It has been eight years since Jennifer initially worked with Jamal, but she ran into him recently; he is now in college and hopes to be a police officer. Given that Jennifer's interaction with Jamal was limited, the vignette does not have as much detail and depth as the previous vignette.

The third vignette comes from the same Media class in a high school in an urban context in Southern Ontario where Jennifer conducted research eight years ago. The Media teacher and Jennifer recognized that students were creating short films about a range of topics outside of the classroom, and felt creating short films would be a fitting assignment for the group. One student named Ahmed stood out for Jennifer. Ahmed is Somalian and always sat with the same two friends. All three of them spoke at length about what it was like to be Muslim post-9/11. All three young men decided to produce a short film on the topic. Jennifer did not get to know the young men very well; they seemed a bit distant and hesitant with her. Ahmed stands out for Jennifer because he was meticulous and exacting about angles, framing, and his script. Jennifer noticed Ahmed's attention to detail because he otherwise seemed quite apathetic in Media class.

What Jennifer remembers most about Ahmed is how staged everything was as he filmed the short rant. Looking directly into the camera, Ahmed recounted what happened on September 11, 2001 and how it impacted his life as a young Muslim male. After doing several rehearsals prior to filming, Ahmed knew what flight of stairs he would climb, and the various angles of his head when he faced the audience and looked away. He scripted the whole video, and the script and performance had a degree of pathos that stood out. There was a marked sense of shame about $9 / 11$, and consternation about being Muslim. In Figure 4, Ahmed is shown walking down the stairs with his eyes cast downwards reflecting on the topic. Rewatching the film today the non-representational nuances that were evident during filming, such as Ahmed's earnestness and his meticulous attention to details, are still clear for Jennifer. 


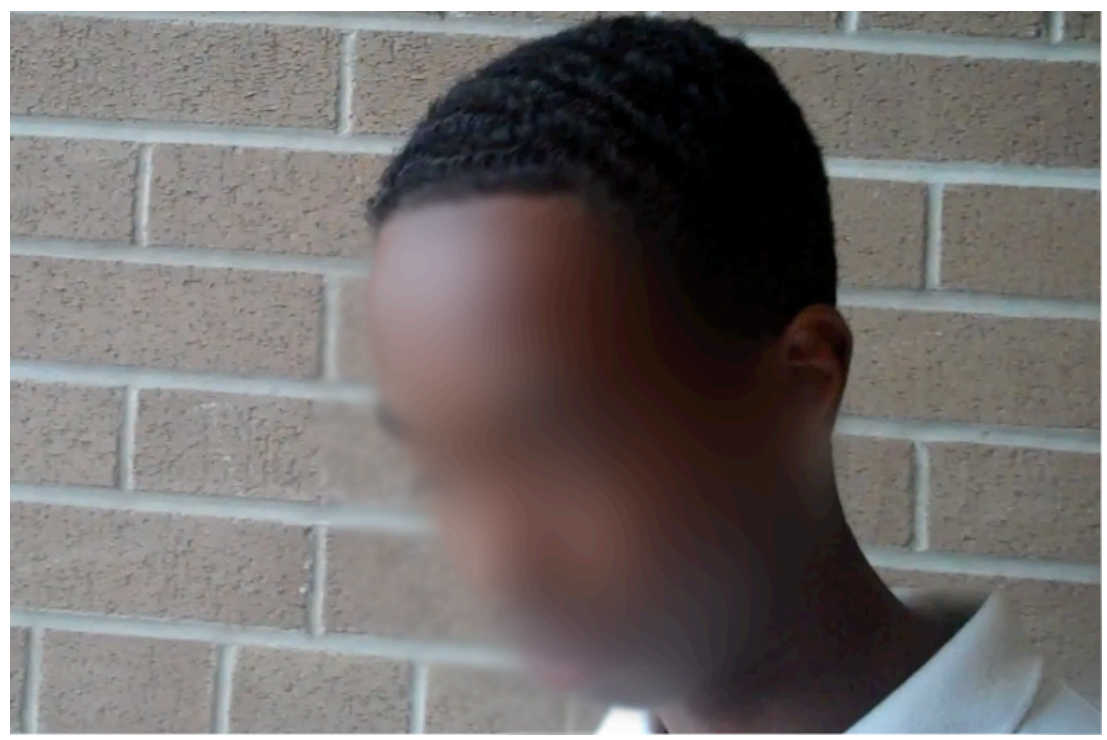

Figure 4. Ahmed's 9/11 film

\section{Moving to Experiencing and Expressing Visual Research}

The lives and narratives documented and reported through sensory-visual methods in this article provide a mosaic of the ideas, passions, and dreams of racialized young men. This is significant because some of these young men were previously labeled as troubled by traditional forms of education. A key benefit of conducting sensory-visual and ethnographic research is being with research participants. There is an essence to the research experience that becomes opaque when written up into an article. There are sounds, smells, spaces, and other people that populate research contexts in powerful, emplaced, and embodied ways. In this way the non-representational plays as much of a role as the representational.

Through a visual analysis of artistic expressions among Black Young Men, we are able to observe some of the many ways they create in the world, and examine what they believe to be possible. Although this article mirrors the transformational characteristics of multiliteracies (Cope \& Kalantzis, 2009), the authors are still aware that young people of color, particularly Black Young Men, are rarely acknowledged for their humanity and complex relationships with literacy (Kirkland, 2008). These young men choose these modes of cultural production to present their lived experiences. They find spaces where they feel safe and free from the pressures of ridicule and harassment. Many of the young men presented in this article have had a difficult time in school; however, our research provides an opportunity for 
personal empowerment so they can exist beyond the realm of failure. These narratives are important because they postulate a counter-narrative to how these young men are typically imagined, schooled and spoken about. TD, Ahmed, Jasper, Jamal, and Ebele continue to share their narratives through photographs, films, rapping and spoken word poetry. They particularly take pride in sharing their narratives with youth and children in the urban and suburban communities they grew up in. These narratives are meant to encourage, motivate and inspire other youth of color to dream and then pursue their dreams.

The telling of such narratives relies heavily on humane qualities of literacy that deal centrally with emotions and the body. The visual is certainly there, as researchers taking photographs capture a moment in time and space. But to us, agency becomes unmoored in images without the sensory framing of it. Pink's (2009) point that sensory ethnography captures the essence of the experience is fundamental to the research that we conduct. We believe that it moves beyond mere visual reporting to experiencing and expressing visual research.

Though Johnson (2017), Kirkland (2013), Morrell (2006), Winn (2010), Kinloch (2010), Rowsell (2011), Gosine and Tabi (2016) and others have underlined and theorized the robust literacy practices of youth of color, there is still extensive work to be done. Our youth are brilliant, resourceful and technologically advanced in ways that we researchers seek to understand. It is precisely for this reason that we are beholden to adapt our research methods to capture the richly varied nature of contemporary meaning-making that screams out at us when we look. However, our youth continue to resist moments of poverty, police brutality, bullying and at times hopelessness. The narratives they share with one another are ripe with wisdom, resistance and courage. It is imperative that we as researchers continue to work with our youth to develop strategies, curriculum, and programs that serve to assist them in a dynamic and complex world.

\section{References}

Barton, D., \& Hamilton, M. (1998). Local literacies: Reading and writing in one community. London: Routledge.

Bloome, D., \& Green, J. (2015). The social and linguistic turns in studying language and literacy. In J. Rowsell \& K. Pahl (Eds.), The Routledge handbook of literacy studies (pp. 19-34). London: Routledge.

Bryan, N., Johnson, L., \& Williams, T. M., (2016). Preparing Black male teachers for the gifted classroom: Recommendations for historically Black colleges and universities (HBCUS). The Journal of Negro Education, 85(4), 489-504.

Cooper, F. R. (2006). Against bipolar Black masculinity: Intersectionality, assimilation, identity performance, and hierarchy. UC Davis Law Review, 39, 853-906.

Cope, B., \& Kalantzis, M. (2000). Multiliteracies: The beginning of an idea. In B. Cope \& M. Kalantzis (Eds.), Multiliteracies: Literacy learning and the design of social futures (pp. 38). London: Routledge.

Cope, B., \& Kalantzis, M. (2009). Multiliteracies: New literacies, new learning. Pedagogies: An International Journal, 4(3), 164-195. 
Dei, G, J. S. (1997). Race and the production of identity in the schooling experiences of AfricanCanadian youth. Discourse: Studies in the Cultural Politics of Education, 18(2), 241-257.

Dei, G. J. S. (2006). "We cannot be colour-blind"e: Race, anti-racism and the subversion of dominant thinking." In W. Ross \& V. Ooka Pang (Eds.), Race, ethnicity, and education (pp. 25-42). Westport, CT: Praeger Publishing.

Dénommé-Welch, S., \& Rowsell, J. (2017). Epistemologies of silence. Brock Education Journal, 27(1), 3-9.

Dicks, B., Flewitt, R., Lancaster, L., \& Pahl, K. (2011). Multimodality and ethnography: Working at the intersection. Qualitative Research, 11(3), 227-237.

Ehret, C., Hollett, T., \& Jocius, R. (2016). The matter of new media making: An intra-action analysis of adolescents making a digital book trailer. Journal of Literacy Research, 48(3), 346-377.

Enriquez, G., Johnson, E., Kontovourki, S., \& Mallozzi, C. A. (Eds.). (2015). Literacies, learning, and the body: Putting theory and research into pedagogical practice. New York: Routledge.

Finnegan, R. (1986). The relations between composition and performance: Three alternative modes. In T. Yoshihiko \& Y. Osamu (Eds.), The oral and literate in music (pp.73-86). Tokyo: Academia Music.

Finnegan, R. (2002). Communicating: The multiple modes of human interconnection. London: Routledge.

Fisher, M. T. (2003). Open mics and open minds: Spoken word poetry in African diaspora participatory literacy communities. Harvard Educational Review, 73(3), 362-389.

Gee, J. P. (1986). Orality and literacy: From the savage mind to ways with words. TESOL Quarterly, 20(4), 719-746.

Geertz, C. (1973). The interpretation of cultures. New York: Basic Books.

Gosine, K., \& Tabi, E. (2016). Disrupting neoliberalism and bridging the multiple worlds of marginalized youth via hip-hop pedagogy: Contemplating possibilities. Review of Education, Pedagogy, \& Cultural Studies, 38(5), 445-467.

Graff, H. (1982). The legacies of literacy. Journal of Communication, 32(1), 12-26.

Green, J., \& Bloome, D. (1997). Ethnography and ethnographers of and in education: A situated perspective. In J. Flood, S. B. Heath \& D. Lapp (Eds.), Handbook of research on teaching literacy through the communicative and visual arts (pp. 181-202). New York: Macmillan.

Grenfell, M., Bloome, D., Hardy, C., Pahl, K., Rowsell, J., \& Street, B. (2012). Language, ethnography, and education: Bridging new literacy studies and Bourdieu. New York: Routledge.

Haddix, M., \& Sealey-Ruiz, Y. (2012). Cultivating digital and popular literacies as empowering and emancipatory acts among urban youth. Journal of Adolescent \& Adult Literacy, 58(3), 189-192.

Heath, S. B. (1983). Ways with words: Language, life and work in communities and classrooms. Cambridge: Cambridge University Press.

Hill, M. L. (2009). Wounded healers: Forming a community through storytelling in Hip-Hop Lit. Teachers College Record, 111(1), 248-293.

Hudson, A., \& Tabi, E. (2015). Where we @?: Blackness, indigeneity, and hip-hop's expression of creative resistance. In S. Steinberg \& A. Ibrahim (Eds.), Critically researching youth (pp. 249-266). New York: Peter Lang.

Hull, G., \& Schultz, K. (2002). School's out! Bridging out-of-school literacies with classroom practice. New York: Teachers College Press.

James, C. E. (2010). Race and well-being: The lives, hopes, and activism of African Canadians. Black Point, N.S: Fernwood.

James, C. E. (2012). Students "at risk": Stereotypes and the schooling of Black boys. Urban Education, 47, 464-494.

Johnson, L. L. (2017). The racial hauntings of one Black male professor and the disturbance of the self(ves): Self actualization and racial storytelling as pedagogical practices. Journal of Literacy Research, 49(4), 476-502.

Johnson, L. L., \& Bryan, N. (2017). Using our voices, losing our bodies: Michael Brown, Trayvon Martin, and the spirit murders of Black male professors in the academy. Race, Ethnicity and Education, 20(2), 163-177. 
Johnson, L. L., Jackson, J., Stovall, D. O., \& Baszile, D. T. (2017). Loving Blackness to death: (Re)Imagining ELA classrooms in a time of racial chaos. English Journal, 106(4), 60-66.

Kinloch, V. (2007). Youth representations of community, art, and struggle in Harlem. New Directions for Adult and Continuing Education, 116, 37-49.

Kinloch, V. (2010). To not be a traitor of Black English: Youth perceptions of language rights in an urban context. Teachers College Record, 112(1), 103-141.

Kirkland, D. (2008). The rose that grew from concrete: Postmodern Blackness and new English education. English Journal, 97(5), 69-75.

Kirkland, D. (2009). The skin we ink: Tattoos, literacy, and a new English education. English Education, 41(4), 375-395.

Kirkland, D. (2013). A search past silence: The literacy of young Black men. New York: Teachers College Press.

Ladson-Billings, G. J. (1998). Just what is critical race theory and what's it doing in a nice field like education. Qualitative Studies in Education, 11(1), 7-24.

Ladson-Billings, G. J., \& Tate, W. F. (1995). Toward a critical race theory of education. Teachers College Record, 97(1), 47-68.

Leander, K. M., \& Boldt, G. M. (2013). Rereading "a pedagogy of multiliteracies": Bodies, texts, and emergence. Journal of Literacy Research, 45(1), 22-46.

Lewis, C., \& Tierney, J. (2013). Mobilizing emotion in an urban classroom: Producing identities and transforming signs in a race-related discussion. Linguistics and Education, 23, 289-304.

Lopez, I. (2000). The social construction of race. In R. Delgado \& J. Stefancic (Eds.), Critical race theory: The cutting edge (pp. 191-203). Philadelphia, PA: Temple University Press.

Mahiri, J., \& Sablo, S. (1996). Writing for their lives: The non-school literacy of urban, African American youth. Journal of Negro Education, 65(2), 164-180.

Massumi, B. (2002). Parables for the virtual: Movement, affect, sensation. Durham, NC: Duke University Press.

Mitchell, C., De Lange, N., \& Moletsane, R. (2017). Participatory visual methodologies. Thousand Oaks, CA: Sage.

Morrell, E. (2006). Critical participatory action research and the literacy achievement of ethnic minority groups. 55 $5^{\text {th }}$ Annual Yearbook of the National Reading Conference, 55, 60-78.

Nasir, N (2011). Racialized identities. Stanford, CA: Stanford University Press

Ogbu, J. U., \& Simons, H. D. (1998). Voluntary and involuntary minorities: A cultural-ecological theory of school performance with some implications for education. Anthropology \& Education Quarterly, 29(2), 155-188.

Pahl, K., \& Rowsell, J. (2010). Artifactual literacies: Every object tells a story. New York: Teacher's College Press.

Pahl, K., \& Rowsell, J. (2011). Artifactual critical literacies: A new perspective for literacy education. Berkeley Review of Education, 2(2), 129-151.

Paris, D. (2012). Culturally sustaining pedagogy: A needed change in stance, terminology and practice. Educational Researcher, 41(3), 93-97.

Parker, L., \& Lynn, M. (2002). What's race got to do with it? Critical race theory's conflicts with and connections to qualitative research and epistemology. Qualitative Inquiry, 8(1), 7-22.

Pink, S. (2009). Doing sensory ethnography. London: Sage.

Pink, S. (2011). Sensory digital photography: Re-thinking moving and the image. Visual Studies, 26(1), 4-13.

Pink, S. (2015). Doing sensory ethnography (2nd ed.). London: Sage.

Rose, G. (2007). Visual methodologies: An introduction to the interpretation of visual material (2nd ed.). London: Sage.

Rowsell, J. (2009). Artifactual English: Transitional objects as a way into English teaching. In M. Hagood (Ed.), New literacies practices: Designing literacy learning (pp. 113-133). New York: Peter Lang.

Rowsell, J. (2011). Carrying my family with me: Artifacts as emic perspectives. Qualitative Research, 11, 331-346.

Rowsell, J., \& Decoste, E. (2012). (Re)designing writing in English class: A multimodal approach to teaching writing. Pedagogies: An International Journal, 7(3), 246-260. 
Rowsell, J., \& Kendrick, M. (2013). Boys' hidden literacies: The critical need for the visual. Journal of Adolescent \& Adult Literacy, 56(7), 587-599.

Rowsell, J., Kress, G., \& Street, B. (2012). Visual optics: Interpreting body art, three ways. Visual Communications, 12(1), 97-122.

Rowsell, J., \& Pahl, K. (2007). Sedimented identities in texts: Instances of practice. Reading Research Quarterly, 42(3), 388-401.

Rowsell, J., \& Pahl, K. (2015). Introduction. In J. Rowsell \& K. Pahl (Eds.) The Routledge handbook of literacy studies (pp. 1-16). London: Routledge.

Rowsell, J., \& Vietgen, P. (2017). Embracing the unknown in community arts zone visual arts. Pedagogies: An International Journal, 12(1), 90-107.

Solorzano, D. G., \& Bernal, D. D. (2001) Examining transformational resistance through a critical race and latcrit theory framework: Chicana and Chicano students in an urban context. Urban Education, 36(3), 308-342.

Solorzano, D. G., \& Yosso, T. (2002). Critical race methodology: Counter-storytelling as an analytical framework for education research. Qualitative Inquiry, 8(23), 23-44.

Somerville, M. J. (2008). A place pedagogy for 'global contemporaneity'. Educational Philosophy \& Theory, 42(3), 326-344.

St. Pierre, E. A. (2013). The posts continue: Becoming. International Journal of Qualitative Studies in Education, 26(6), 646-657.

Stovall, D. (2006). Urban poetics: Poetry, social justice, and critical pedagogy in education. Urban Review, 38(1), 63-80.

Street, B. (1984). Literacy in theory and practice. Cambridge: Cambridge University Press.

Street, B. V. (1993). Culture is a verb: Anthropological aspects of language and cultural process. In D. Graddol, L. Thompson \& M. Byram (Eds.), Language and culture (pp. 23-43). Clevedon, UK: British Association of Applied Linguistics.

Toronto District School Board. (2007). 2006 student census, grades 7-12: System overview. Toronto: Toronto District School Board.

Walcott, R. (2012). Canadian men and masculinities: Blackness, masculinity, and the work of Queer. In C. J. Greig \& W. J. Martino (Eds.), Canadian men and masculinities: Historical and contemporary perspectives (pp. 191-204). Toronto: Canadian Scholars Press.

Winn, M. T. (2010). Betwixt and between: Literacy, liminality, and the celling of Black girls. Race, Ethnicity \& Education, 13(4), 425-447.

Wolcott, H. (2001). Writing up qualitative research (2nd ed.). Newbury Park, CA: Sage.

Yosso, T. J. (2005). Whose culture has capital? A critical race theory discussion of community cultural wealth. Race, Ethnicity \& Education, 8(1), 69-91. 